\title{
An integrated grazingland assessment approach for range and pasturelands
}

\author{
D. Toledo, M. Sanderson, S. Goslee, J. Herrick, and G. Fults
}

\begin{abstract}
In the United States, rangelands and pasturelands have traditionally been assessed using different methods and indicators. The most commonly used rangeland health assessment protocol on US rangelands is the Interpreting Indicators of Rangeland Health (IIRH) assessment, while pasturelands are usually assessed using the Pasture Condition Score (PCS) system. The IIRH method provides a way of detecting changes in ecological attributes relative to a site's ecological potential. PCS informs managers about the utility of an area for livestock production or factors that could be keeping the area from operating at its full or optimized productive potential. There is a need for an improved grazingland assessment tool that merges the relevant elements of both the rangeland and pastureland assessment methods while taking into account the differing ecosystem attributes and management objectives of the grazinglands where these methods are usually applied. We use IIRH and PCS data collected at two locations in the Northern Great Plains of the United States to describe our approach and demonstrate its usefulness. We present an improved grazingland assessment protocol that is applicable to range and pasturelands that highlights the complementarity of the IIRH and PCS approaches. This improved assessment and monitoring protocol allows evaluators to assess site conditions and to make interpretations regarding management based on site-specific attributes. Standardized grazingland assessment and monitoring protocols based on ecological and land management principles will ultimately improve national level assessments and will provide a valuable and efficient tool for assessing, managing, and monitoring grazinglands.
\end{abstract}

Key words: grazingland - integrated grazingland assessment-pasture-pasture condition score-rangeland-rangeland health

In the United States, rangelands and pasturelands have traditionally been assessed using different methods and indicators. Field work, research (Sanderson et al. 2014; Goslee et al. 2014; Toledo et al. 2014), focus group meetings, and personal observation from participation at national trainings revealed almost complete consensus on the need for an improved grazingland assessment tool and complete agreement that both Interpreting Indicators of Rangeland Health (IIRH; Pellant et al. 2005) and Pasture Condition Scoring (PCS; Cosgrove et al. 2001) serve different and yet important roles in grazingland assessments. An improved, standardized grazingland assessment and management protocol based on ecological and land management principles will serve to improve national level assess- when a reduction does occur;" and (3) biotic integrity, which refers to "the capacity of the biotic community to support ecological processes within the normal range of variability expected for the site, to resist a loss in the capacity to support these processes, and to recover this capacity when losses do occur. The biotic community includes plants, animals, and microorganisms occurring both above and below ground" (Pellant et al. 2005). IIRH identifies what needs to be monitored and possibly leads to specifics of a goal in management changes, but users are provided little guidance on how to apply evaluations to management.

IIRH has been used widely in rangelands (Duniway et al. 2010; Herrick et al. 2010), but it has not been broadly applied in areas devoted to the production of introduced or indigenous forage for harvest by grazing, cutting, or both, commonly referred to as pastures. PCS assessments include evaluating ecological indicators that are already incorporated and evaluated at a broad scale in IIRH such as erosion and compaction, but the metrics used for these assessments in PCS do not allow for cross site comparisons, which IIRH indicators do.

The PCS system was developed by the USDA Natural Resources Conservation Service (NRCS) as a monitoring and management tool for pasturelands (Cosgrove et al. 2001). Pasture condition refers to "the status of the plant community and the soil in a pasture in relation to its highest possible condition under ideal management." Ten indicators of vegetation and soil status are rated on a one to five scale and are summed to give an aggregate score, which is evaluated and interpreted together with potential causative factors to make management recommendations (Sanderson et al. 2009). PCS does not use site-specific reference condi-

David Toledo is a research rangeland management specialist and Matt Sanderson is a research leader at the USDA Agricultural Research Service (ARS) Northern Great Plains Research Laboratory in Mandan, North Dakota. Sarah Goslee is an ecologist at the USDA ARS Pasture Systems and Watershed Management Research Unit in University Park, Pennsylvania. Jeffrey Herrick is a research soil scientist at the USDA ARS Research Unit at The Jornada in Las Cruces, New Mexico. Gene Fults is a rangeland management specialist at the USDA Natural Resources Conservation Service (NRCS) West National Technology Support Center in Portland, Oregon. 
tions with which to make assessments, like the IIRH does. Rather, assessments are made against an ideal management standard. The strength of PCS data and assessments lies in its ability to provide management interpretations and recommendations, particularly for causative factors to manage plant vigor, which IIRH does not do. Our proposed approach takes indicators from PCS that we believe are applicable to all grazinglands and includes them into a core set of grazingland assessment indicators. We have created a management attribute called "livestock carrying capacity" (LCC) and have provided a rating system by which grazingland assessments can be used to guide management decisions.

The IIRH protocol provides a way to assess and interpret soil and site stability, biotic integrity, and hydrologic function attributes based on ecological potential at a site. The PCS protocol provides a framework for planning and assessing management at a site. We integrate the two protocols into a single grazingland assessment tool by merging the IIRH tools for ecological assessments relative to site potential and the management interpretation tools for enhanced LCC from PCS. This improved assessment and monitoring protocol allows evaluators to assess site conditions and to make interpretations regarding management based on site-specific attributes that can potentially optimize the ecological potential and LCC of a site.

Functional Attributes and an Integrated Approach. The integrated grazingland assessment approach expands on the strengths of the IIRH and PCS methods to provide a detailed assessment of the ecological attributes of an area and assess how an area is being managed. For this, the integrated approach is based on attributes of rangeland health as well as an attribute related to grazingland management. These foundational attributes include soil and site stability, hydrologic function, biotic integrity, and LCC. These attributes contribute to the primary ecosystem service provided by grazinglands, that of forage/fodder production, and to additional services such as sequestration of soil carbon (C), nutrient cycling, and prevention of soil erosion (Nelson 2012).

"Livestock carrying capacity" refers to the ability of an area to support a sustainable livestock grazing operation and is a new contribution to the list of attributes. This attribute incorporates elements of grazing management and the suitability of the current plant community for livestock production. Management interpretations based on this attribute are based on the ecological potential of a site. By applying management practices such as irrigation, fertilization, or seeding of specific plant varieties, this potential can be increased. Assessing the potential for livestock production of a site and the capacity to increase that production based on site-specific attributes provides a way of realistically optimizing management based on a site's ecological potential. Our approach allows evaluators to determine management actions that are likely to result in cost effective enterprise efforts that will result in improved grazingland health and increased carrying capacity. These management actions include but are not limited to the following:

- Grazing management change: type, timing, frequency, intensity of grazing achieved through a change in herd composition, numbers or rotation schedule through herding or fencing, location of water sources (gravelly or constructed stable livestock stream crossing[s] or watering $\operatorname{ramp}[\mathrm{s}]$; or alternative water sources present and close-by)

- Erosion control

- Fertility change

- Targeted control of one or more species (mechanical or herbicide)

- Tillage (stand replacement)

- Seeding

- Prescribed fire (limited situations)

Ecological attributes in the integrated approach are based on the potential of an area. The baseline potential is based on climatic, topo-edaphic, and ecological factors, which are included in Ecological Site Descriptions (USDA NRCS 2011). However, this potential can be exceeded for livestock management purposes through the use of conservation practices and other agronomic management techniques (Briske 2011; Nelson 2012) that can increase the LCC of an area. Proper application of conservation and/or agronomic practices combined with adequate monitoring and assessment techniques can allow a site to sustainably improve its LCC. On the contrary, lack of proper monitoring and assessment can lead to natural resource issues going undetected and thus affecting the long-term carrying capacity of grazinglands.

There is a need for a national level assessment and monitoring protocol that allows evaluators to assess grazingland conditions at the national scale. Our objective is to use IIRH and PCS data collected in the Northern Great Plains of the United States to present a proposed improved grazingland assessment protocol that is applicable to both range and pasturelands and that highlights the complementarity of the IIRH and PCS approaches. It is important to note that this is an assessment tool intended for national level assessments such as the USDA NRCS rangeland National Resource Inventory, and it is not intended as an NRCS pastureland planning tool. PCS has been effectively used as a planning tool for over a decade and there are current efforts underway to update PCS for this specific purpose.

\section{Materials and Methods}

Study Sites. This study was performed at two different locations in the Northern Great Plains region of the United States: the USDA Agricultural Research Service (ARS) Northern Great Plains Research Lab (NGPRL, $n=11$ ) near Mandan, North Dakota, and the USDA ARS Central Plains Experimental Range (CPER, $n=6$ ) (figure 1) near Nunn, Colorado. Study locations represented two different grazinglands with a variety of historical vegetation compositions and management histories. The NGPRL is at the geographic and climatic boundary between rangelands and pasturelands, and plots at this site could be considered as either pastureland or rangeland, while the CPER is located in an area traditionally thought of as rangeland (figure 1). Our analysis only includes plots that were located on loamy ecological sites. For the NGPRL this ecological site corresponded to site R054XY031ND, and for the CPER the ecological site was site R067BY002CO (Ecological Site Descriptions available online at https://esis.sc.egov.usda.gov).

Assessment Procedure. A circular macroplot of $45.72 \mathrm{~m}(150 \mathrm{ft})$ in diameter and an area of 1,642 $\mathrm{m}^{2}\left(17,670 \mathrm{ft}^{2}\right)$ was established following USDA NRCS On-Site Grazing Land Study National Resource Inventory (NRI) plot protocols (Spaeth et al. 2003; USDA NRCS 2009). Within each NRI macroplot, we used the line-point intercept, plant height, and plant census methods to collect indicators for plant cover, species richness and plant diversity, bare ground, and plant height. The quantitative methods performed by the NRI are not a required 


\section{Figure 1}

Location of USDA Agricultural Research Service (ARS) Northern Great Plains Research Laboratory (NGPRL) and USDA ARS Central Plains Experimental Range (CPER) study sites in relation to grazingland cover in the continental United States based on the 2011 National Land Cover Database (Jin et al. 2013).

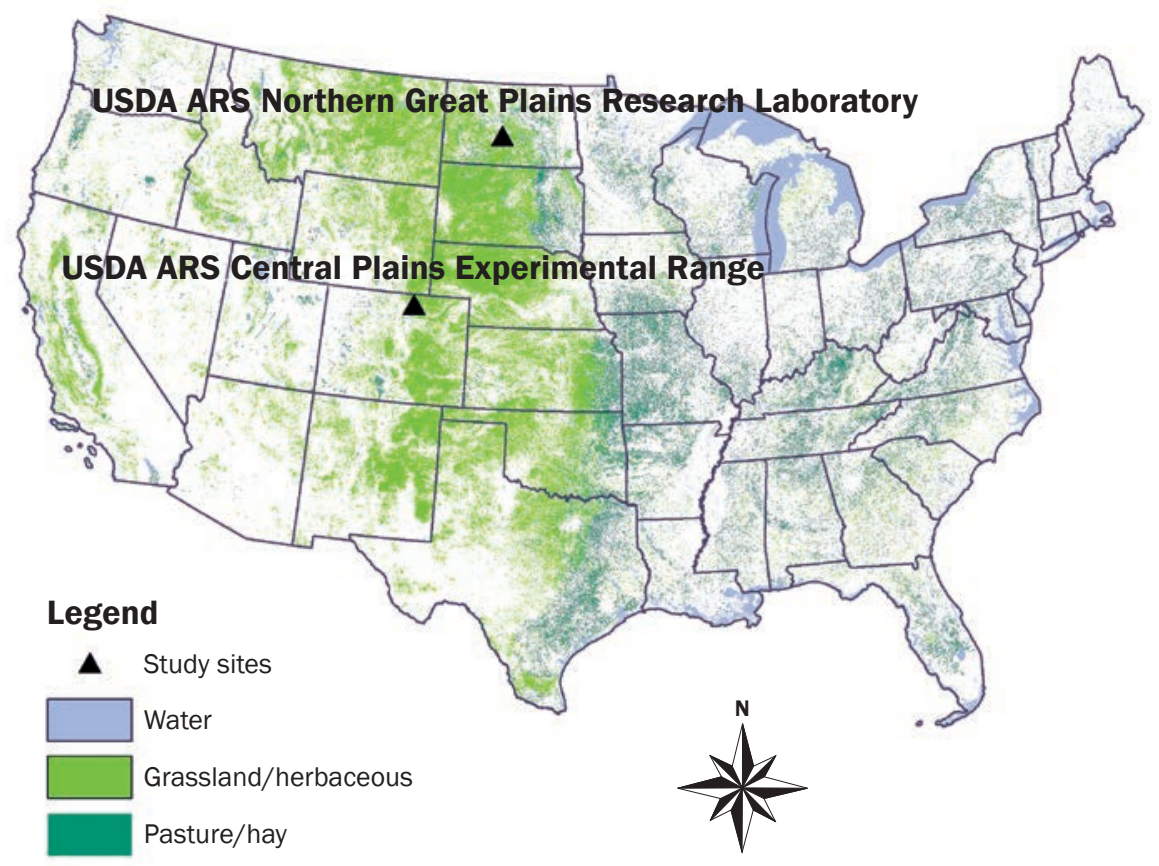

component of either the IIRH or PCS, but they can help support indicator ratings made with qualitative assessments. For the purpose of this study, NRI methods also provided a way of informing qualitative assessment data with quantitative data collected using nationally accepted methods. Rangeland health assessments were performed using IIRH protocols (Pellant et al. 2005), which evaluate 17 indicators (table 1) to rate the attributes of soil and site stability, hydrologic function, and biotic integrity. Attribute ratings in the IIRH protocol are evaluated by using a preponderance of evidence approach, where the rating is made based on where the majority of the indicators for each attribute fall under the five rating categories (none to slight, slight to moderate, moderate, moderate to extreme, and extreme to total). However, if an indicator is particularly important for a site (e.g., bare ground), an attribute rating could be weighted based on this indicator (Pellant et al. 2005). For this study we determined attribute scores based on the rating of the majority of indicators for that attribute to facilitate comparisons. For example, if four of the soil/site stability indicators are in the "moderate" and six are in the "slight to moderate" departure category, the soil/site stability attribute would be rated as "slight to moderate" (Pellant et al. 2005). PCS was done using the 10 indicators of vegetation and soil status (table 2) presented in Cosgrove et al. (2001). These indicators are rated on a one to five scale and are summed to give an aggregate score, which is evaluated and interpreted together with potential causative factors to make management recommendations (Sanderson et al. 2009). We used logistic regression to analyze continuous predictor variables collected using transect-based methods with categorical dependent IIRH and PCS variables.

\section{Results and Discussion}

We present the values for indicators and attributes for each method, and then combine the results of each approach to demonstrate the value of method integration. At the site level, IIRH results (table 3) show that at the NGPRL there was none to slight departure from reference condition in soil and site stability, moderate departure from reference in hydrologic function, and moderate to extreme departure from reference in biotic integrity. The indicators driving most of the departure for these two attributes were plant community composition relative to infil- tration and runoff (IIRH \#10), functional/ structural groups (IIRH \#12), litter amount (IIRH \#14), and invasive plants (IIRH \#16). Line point intercept values as well as plant census data for this site show that Kentucky bluegrass (Poa pratensis L.) and smooth brome (Bromus inermis Leyss.) have invaded these sites with combined bluegrass-brome foliar canopy cover values ranging from $46 \%$ to greater than $100 \%$ (numbers greater than $100 \%$ cover were due to overlapping species foliar cover), affecting species richness and species distribution at these sites (table 4). Logistic regression analysis shows a significant relationship between increasing Kentucky bluegrass and smooth bromegrass cover and decreasing biotic integrity and hydrologic function $\left(r^{2}=0.50, p=0.0058\right.$ and $r^{2}=0.20, p=0.0398$, respectively). PCS data (table 5) at the NGPRL ranged from 26 to 38 of a possible 50 points. The lower PCS scores were attributable to plant diversity (PCS \#3), percentage legumes (PCS \#6), and uniformity of use (PCS \#7).

At the CPER, IIRH shows departure from reference in hydrologic function and biotic integrity attributes with soil surface resistance to erosion (IIRH \#8) and plant functional/structural groups (IIRH \#12) contributing most to that departure (table 3). Line point intercept values as well as plant census data for this site show that some plots have low soil aggregate stability values, which affect all attributes (table 4). In plots 13, 16, and 17, canopy foliar cover ranges from $49 \%$ to $69 \%$, which is low for this site. At these three plots, annual production was also reduced and the percentage of bare ground was elevated, ranging from $17 \%$ to $25 \%$. Pasture condition scores at the CPER ranged from 25.5 to 39.5 (table 5) with the reduction in scores attributable to plant cover (PCS \#2), plant diversity (PCS \#3), percentage legume (PCS \#6), and uniformity of use (PCS \#7).

For a site-specific interpretation of results we selected one plot at random from each of the study areas: plot 1 in the NGPRL and plot 15 at the CPER. In plot 1, scores for PCS rated low mostly because of low forage diversity (\#3), low percentage legumes (\#6), reduced plant cover (\#2), increased residue (\#4), not being used uniformly (\#7), and due to some soil compaction (\#9) (table 5). According to the ecological site description (Site ID: R054XY031ND) for this site, some bare ground should have been expected for 


\section{Table 1}

Seventeen indicators used in Interpreting Indicators of Rangeland Health (IIRH) Assessments as described in Pellant et al. (2005) and direct relation to attributes of livestock carrying capacity (LCC). IIRH assessments use 17 indicators to rate three attributes of rangeland health: soil and site stability (SSS), hydrologic function (HF), and biotic integrity (BI).

\begin{tabular}{llll}
\hline $\begin{array}{l}\text { Indicator } \\
\text { no. }\end{array}$ & Indicator & Attribute & Description \\
\hline 1 & Rills & SSS, HF & $\begin{array}{c}\text { Sidecut linear features formed through complex interactions between raindrops, } \\
\text { overland flow, and the characteristics of the soil surface (Bryan 1985). }\end{array}$ \\
& Water-flow patterns & SSS, HF & $\begin{array}{c}\text { The path that water takes as it moves across the soil surface during overland } \\
\text { flow. These patterns are generally evidenced by litter, soil or gravel redistribution, } \\
\end{array}$ \\
& & $\begin{array}{l}\text { or pedestalling of vegetation or stones that break the flow of water (Morgan 1986) } \\
\text { and are rarely continuous. }\end{array}$
\end{tabular}

3

4

5

6

7

8

9

10

12

13

Plant mortality/decadence

14

15

16

Invasive plants

17

Bare ground (\%)

Gullies

Wind-scoured, blowouts, and/or deposition areas

Litter movement

Soil surface resistance to erosion

Soil surface loss or degradation

Plant community composition and distribution relative to infiltration and runoff

Compaction layer
Pedestals and/or terracettes SSS, HF

Functional/structural groups

BI

BI, LCC

$\mathrm{HF}, \mathrm{BI}$

BI, LCC

$\mathrm{BI}$

BI

Reproductive capability

of perennial plants

SSS, HF

SSS

SSS

HF
SSS, HF, BI

SSS, HF, BI

SSS, HF, BI

Near-surface layer of dense soil caused by repeated impacts on or disturbances of the soil surface.

Functional/structural groups are a suite of species that are grouped together. Both the presence of functional groups and the number of species within the groups have a significant effect on ecosystem processes (Tilman et al. 1997).

The proportion of dead or decadent (e.g., moribund, dying) to young or mature plants in the community, relative to that expected for the site under normal disturbance regimes.

Litter is any dead plant material that is detached from the base of the plant.

Annual production, as used in IIRH, is the net quantity of aboveground vascular plant material produced within a year.

Invasive plants are plants that are not part of (if exotic), or are a minor component of (if native), the original plant community or communities that have the potential to become a dominant or codominant species on the site if their future establishment and growth is not actively controlled by management interventions.

An assessment of inflorescence production for sexually reproducing plants and clonal production for vegetatively reproducing plants, relative to what should be expected. 


\section{Table 2}

Indicators for Pasture Condition Scoring (PCS) as described in Cosgrove et al. (2001) and how they relate to attributes described in the integrated approach. These attributes include soil and site stability (SSS), hydrologic function (HF), biotic integrity (BI), and livestock carrying capacity (LCC).

\begin{tabular}{|c|c|c|c|}
\hline $\begin{array}{l}\text { Indicator } \\
\text { no. }\end{array}$ & Indicator & Attribute & Description \\
\hline 1 & Percentage desirable plants & LCC & $\begin{array}{l}\text { Percentage of plants that livestock would readily consume, are persistent, and } \\
\text { provide high tonnage and quality for a significant part of the growing season. }\end{array}$ \\
\hline 2 & Plant cover $(\%)$ & LCC, SSS, HF & The percentage of the soil surface covered by plants. \\
\hline 3 & Plant diversity & LCC & $\begin{array}{l}\text { Plant diversity is the number of different forage plants that are well represented } \\
\text { (20\% or more of plant cover) in a pasture. }\end{array}$ \\
\hline 4 & Plant residue & LCC, HF, BI & Percentage of dead plant material (standing dead, thatch) in a pasture. \\
\hline 5 & Plant vigor & $\mathrm{LCC}, \mathrm{BI}$ & $\begin{array}{l}\text { Overall color, size, rate of regrowth following harvest, and productivity of desirable } \\
\text { and intermediate plant species. }\end{array}$ \\
\hline 6 & Percentage legume & LCC & Percentage of legumes present as total air dry weight. \\
\hline 7 & Uniformity of use & LCC & $\begin{array}{l}\text { Uniformity of animal grazing patterns. Uniform grazing results in all desirable and } \\
\text { intermediate species being grazed to a similar height. }\end{array}$ \\
\hline 8 & $\begin{array}{l}\text { Livestock concentration } \\
\text { areas }\end{array}$ & LCC & $\begin{array}{l}\text { Places in pastures where livestock return frequently and linger to be near water, } \\
\text { feed, mineral or salt, or shelter, or to be in shade. }\end{array}$ \\
\hline 9 & Soil compaction & SSS, HF, BI & $\begin{array}{l}\text { Increased bulk density (weight per volume of soil) of layers at } 2.5 \mathrm{~cm} \text { increments to } \\
\text { plow depth. Can also be detected in the field using a soil probe, metal rod, or knife. }\end{array}$ \\
\hline 10 & Erosion & SSS, HF & $\begin{array}{l}\text { Soil loss cause by wind or water. Evaluated in terms of wind, sheet, and rill erosion or } \\
\text { streambank, shoreline, and gully erosion. }\end{array}$ \\
\hline
\end{tabular}

the site $(10 \%$ to $15 \%)$, there were few native legumes expected to be present, and litter cover should have ranged from $50 \%$ to $60 \%$. IIRH assessment showed departures in plant community composition and distribution relative to infiltration and runoff (\#10), functional/structural groups (\#12), litter amount (\#14), and invasive plants (\#16) (table 3). Invasive plant departure was mainly attributed to Kentucky bluegrass that had come to dominate the site, affecting vegetation composition, function, and structure, and the amount of litter present. Given the information provided in the ecological site description, PCS should have been rated higher based on the site's potential. The combination of IIRH and PCS suggests that reducing Kentucky bluegrass cover and litter amount and planting legumes and forage species would greatly improve the value of this area for livestock production.

For plot 15 at the CPER, PCS scores for plant cover, forage diversity, and percentage legumes appeared to be low. However, upon examination of the IIRH data, it became evident that bare ground had none to slight $(\mathrm{N}-\mathrm{S})$ departure, meaning that some bare patches are a natural occurrence for this site. Ecologically, plot 15 was functioning close to its ecological potential with slight to moderate loss of surface resistance to erosion and moderate decrease in functional structural groups mainly due to cacti increasing in dominance and some important species missing from this site. Therefore, in order to optimize livestock management without considerable inputs and based on current ecological potential, managers should focus on decreasing cacti cover and increasing forage diversity, including the addition of legumes. Additionally, through soil nutrient tests, nutrient additions, and other livestock management practices, a land manager could potentially increase the productive potential of this area.

As an example of the application of the integrated approach we selected plot 1 at the NGPRL, a plot that we discussed above using both IIRH and PCS. Results using the integrated grazingland assessment for this plot (table 6) show a slight variation on how this plot would rate using this assessment protocol and which specific factors are contributing the most to the difference. Assessment of LCC indicators using this site specific approach shows a large deviation in indicator \#18 (percentage desirable forage plants) from a desirable plants score of 4 in PCS to an extreme to total (E-T) departure in the integrated assessment. This difference is because Kentucky bluegrass dominates the site. This cool-season perennial grass has fair to good forage value, but it is not present in the forage suitability group (G054XY100ND) for this plot. Additionally, the ecological site description for this plot (R054XY031ND) shows Kentucky bluegrass as an undesirable invasive plant that can reduce productivity by $70 \%$ to $80 \%$ of potential. Quantitative data for this plot shows $12 \%$ crested wheatgrass (Agropyron cristatum [L.] Gaertn.), 3\% alfalfa (Medicago sativa L.), and trace amounts $(<1 \%)$ of green needlegrass (Nassella viridula [Trin.] Barkworth), which are species found in the forage suitability group description. However, these desirable forage species together do not add up to the $20 \%$ needed to go from the E-T category to the moderate to extreme (M-E) category based on the evaluation matrix for the integrated approach (table 7). Forage diversity (\#19) also deviated between assessment methodologies for this plot, from a plant diversity score of 1 in PCS to an M in the integrated assessment. The two cool season grasses (crested wheatgrass and green needlegrass) and legume (alfalfa) show a patchy distribution throughout the site and therefore fall under the moderate departure from reference category based on the reference matrix. A closer look at how the four attributes rate based on the preponderance of evidence (figure 2) shows that IIRH soil and site stability as well as hydrologic func- 


\section{Table 3}

Interpreting Indicators of Rangeland Health (IIRH) results for loamy ecological site plots at the USDA Agricultural Research Service (ARS) Northern Great Plains Research Laboratory (plots 1 to 11) and the USDA ARS Central Plains Experimental Range (plots 12 to 17). Indicator ratings are based on how departed the indicator is from what it should be in a reference condition. $\mathrm{N}-\mathrm{S}$ refers to none to slight departure from reference; S-M for slight to moderate; $M$ for moderate; $M$-E for moderate to extreme; and E-T for extreme to total departure from reference based on an ecological site description.

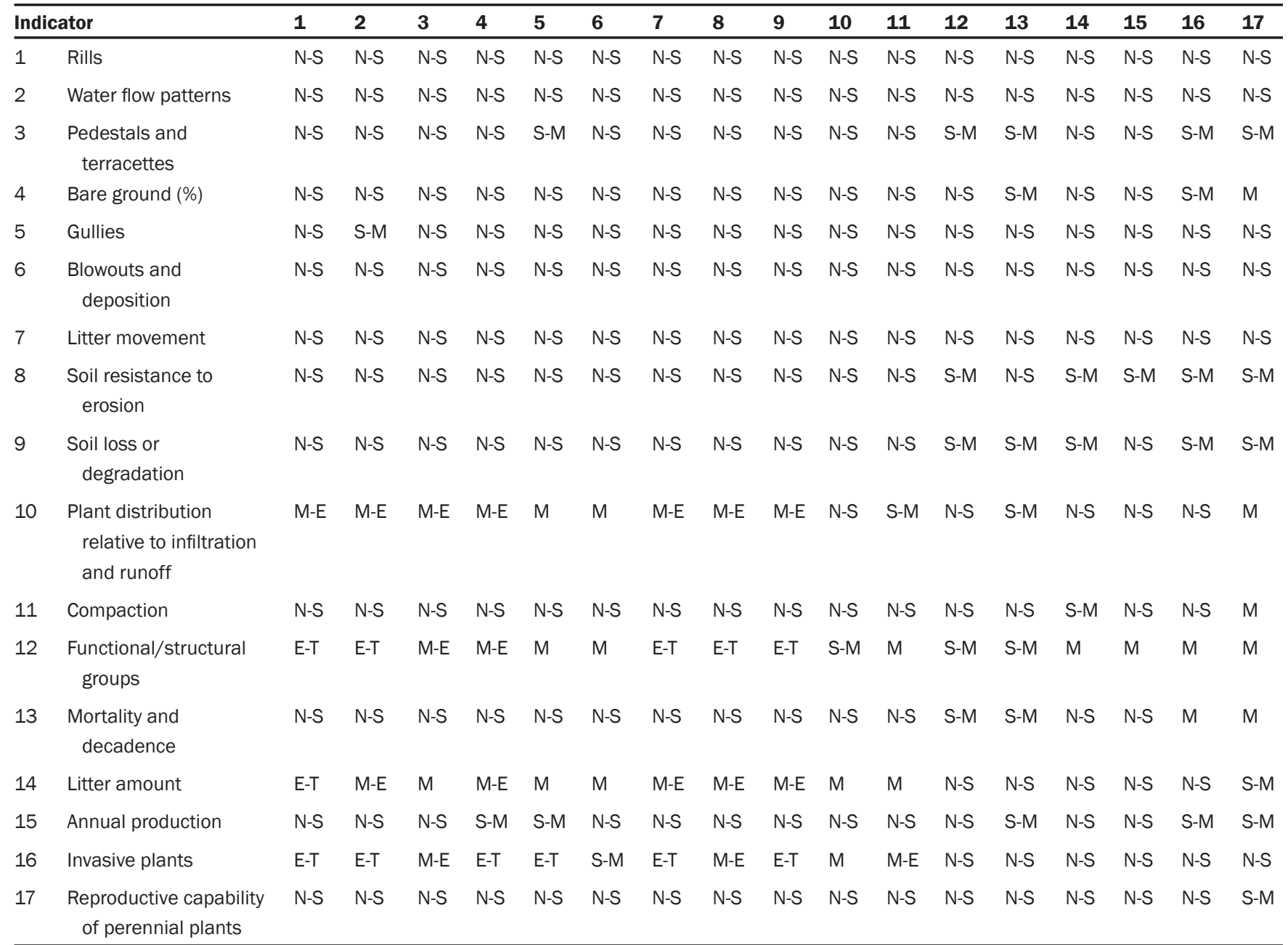

Attribute ratings

$\begin{array}{lllllllllllllllllll}\text { Soil and site stability } & \text { N-S } & \text { N-S } & \text { N-S } & \text { N-S } & \text { N-S } & \text { N-S } & \text { N-S } & \text { N-S } & \text { N-S } & \text { N-S } & \text { N-S } & \text { N-S } & \text { S-M } & \text { N-S } & \text { N-S } & \text { S-M } & \text { S-M } \\ \text { Hydrologic function } & \text { M } & \text { M } & \text { S-M } & \text { M } & \text { S-M } & \text { S-M } & \text { M } & \text { M } & \text { M } & \text { N-S } & \text { N-S } & \text { S-M } & \text { S-M } & \text { S-M } & \text { N-S } & \text { S-M } & \text { S-M } \\ \text { Biotic integrity } & \text { M-E } & \text { M-E } & \text { M } & \text { M-E } & \text { M } & \text { M } & \text { M-E } & \text { M-E } & \text { M-E } & \text { M } & \text { M } & \text { S-M } & \text { S-M } & \text { S-M } & \text { S-M } & \text { M } & \text { M }\end{array}$

tion rate as none to slightly departed from reference condition. IIRH biotic integrity and LCC show a moderate departure from reference condition. Management recommendations to optimize LCC at this site would follow interpretations made above for plot 1 using PCS alone but add more specificity. Adding two to three species of desirable forage plants from one or two different functional groups (e.g., warm-season legume, warm season short grass) and increasing the productivity of the forage plants present by reducing competition from Kentucky bluegrass would improve LCC.
Being careful not to increase the presence of bloating legumes such as alfalfa and instead adding site adapted nonbloating legumes based on the forage suitability group description for this plot (e.g., Dalea purpurea Vent., Dalea candida Michx. Ex Willd., etc) would also help increase LCC.

Changes in ecological attributes are not always immediately visible, and the IIRH method provides a way of detecting these changes relative to a site's ecological potential. IIRH, however, does not inform managers about the utility of these areas for livestock production or factors that could be keeping the area from operating at its full or optimized productive potential. Pasture condition scoring indicators allow managers to determine management options, but current methods are not site-specific and have no standard for comparison. This explains why the PCS indicator for erosion showed a decreased score for a few sites while the IIRH soil and site stability attribute showed no departure.

Management optimization refers to management actions that will maximize the productive potential of a parcel based on a land manager's specific objectives and the 
Table 4

Line-point intercept cover values for all vegetation, Kentucky bluegrass (Poa pratensis L.) and smooth brome (Bromus inermis Leyss.), as well as species richness and species distribution at all loamy sites sampled in the Northern Great Plains Research Laboratory (plots 1 to 11) and Central Plains Experimental Range (plots 12 to 17 ).

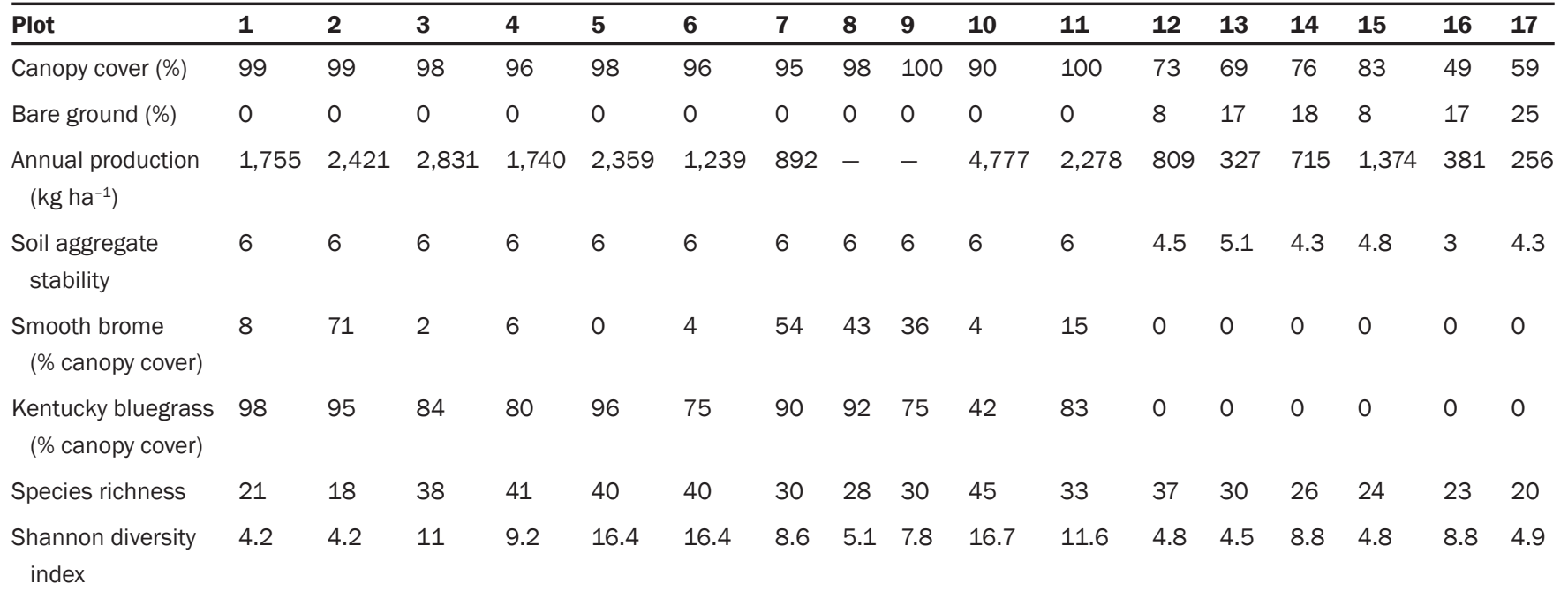

\section{Table 5}

Pasture Condition Scoring results for loamy ecological site plots at the USDA Agricultural Research Service (ARS) Northern Great Plains Research Laboratory (plots 1 to 11) and the USDA ARS Central Plains Experimental Range (plots 12 to 17 ).

\begin{tabular}{|c|c|c|c|c|c|c|c|c|c|c|c|c|c|c|c|c|c|c|}
\hline \multicolumn{2}{|c|}{ Indicator/plot } & \multirow{2}{*}{$\frac{1}{4}$} & \multirow{2}{*}{$\frac{2}{3}$} & \multirow{2}{*}{$\frac{3}{2}$} & \multirow{2}{*}{$\frac{4}{2}$} & \multirow{2}{*}{$\frac{5}{2}$} & \multirow{2}{*}{$\frac{6}{4}$} & \multirow{2}{*}{$\frac{7}{3}$} & \multirow{2}{*}{$\frac{8}{3}$} & \multirow{2}{*}{$\frac{9}{3}$} & \multirow{2}{*}{$\frac{10}{3}$} & \multirow{2}{*}{$\frac{11}{2}$} & \multirow{2}{*}{$\frac{12}{5}$} & \multirow{2}{*}{$\frac{13}{3}$} & \multirow{2}{*}{$\frac{14}{3}$} & \multirow{2}{*}{$\frac{15}{4}$} & \multirow{2}{*}{$\frac{16}{2}$} & \multirow{2}{*}{$\frac{17}{3}$} \\
\hline 1 & Percentage desirable plants & & & & & & & & & & & & & & & & & \\
\hline 2 & Plant cover (\%) & 3 & 3 & 2 & 3 & 2 & 3 & 3 & 4 & 3 & 5 & 5 & 4 & 2 & 2 & 3 & 2 & 1 \\
\hline 4 & Plant residue & 3 & 3 & 4 & 3 & 4 & 3 & 4 & 3 & 2 & 3 & 3 & 3.5 & 4 & 4 & 5 & 4.5 & 2.5 \\
\hline 5 & Plant vigor & 4 & 4 & 4 & 4 & 3 & 4 & 4 & 4 & 4 & 4 & 4 & 4 & 2 & 3 & 4 & 2 & 2 \\
\hline 6 & Percentage legume & 1 & 2 & 1 & 1 & 1 & 1 & 1 & 1 & 1 & 1 & 1 & 1 & 1 & 1 & 1 & 1 & 1 \\
\hline 8 & Livestock concentration areas & 5 & 5 & 5 & 5 & 4 & 4 & 4 & 5 & 5 & 5 & 5 & 5 & 4 & 4 & 5 & 5 & 4 \\
\hline 9 & Soil compaction & 4 & 4 & 5 & 5 & 5 & 5 & 5 & 4 & 4 & 5 & 5 & 5 & 3 & 4 & 5 & 5 & 3 \\
\hline 10 & Erosion & 5 & 5 & 5 & 4 & 3 & 4 & 4 & 5 & 5 & 5 & 5 & 5 & 4 & 4 & 5 & 4 & 4 \\
\hline & ndition Score & 33 & 34 & 31 & 30 & 26 & 33 & 31 & 34 & 33 & 38 & 35 & 40 & 29 & 30 & 38 & 34 & 26 \\
\hline
\end{tabular}

ecological potential of an area. Management actions may include but are not limited to changes in infrastructure, livestock type, grazing timing, livestock feed supplementation, vegetation manipulation, and agronomic inputs. Agronomic inputs include but are not limited to seeding, fertilization, soil amendments, pest control, drainage, and irrigation (Butler et al. 2003), and are especially important in those lands typically referred to as pasturelands. An important differentiation between agronomic inputs and other management actions is that through these types of inputs, land managers may increase the productive potential of an area beyond the baseline possible if the area were man- aged as a natural ecosystem. Ecological site descriptions characterize the vegetation and productivity of an area based on a site's ecological potential. Agronomic inputs are part of a manager's toolbox and may be appropriate in many cases, but it is also important to note that this type of management can have adverse effects on ecosystem structure and function, and if not monitored and managed adaptively, can reduce the long-term sustainability of a management operation.

Despite the ability to increase productive potential through agronomic inputs, it is important to keep in mind that treatments in a degraded area will not have the intended consequences unless the factors causing degra- dation are addressed. As stated in the National Range and Pasture Handbook (Butler et al. 2006), "agronomic solutions to forage growth enhancement will only be as effective as that grazing management regime allows."

While developing the framework described above and during previous research (Toledo et al. 2014), we identified indicator redundancies and methodological deficiencies. The main deficiencies have been stated earlier and include lack of management interpretations in IIRH and lack of reference conditions in PCS. Integrating IIRH and PCS into a common grazingland assessment approach takes care of these deficiencies, but generates a series of redundancies (Toledo 


\begin{tabular}{|c|c|c|c|}
\hline $\begin{array}{l}\text { Indicator } \\
\text { no. }\end{array}$ & Indicator & Attribute & Rating \\
\hline 1 & Rills & SSS, HF & N-S \\
\hline 2 & Water-flow Patterns & SSS, HF & N-S \\
\hline 3 & Pedestals and/or terracettes & SSS, HF & N-S \\
\hline 4 & Bare ground (\%) & SSS, HF, LCC & N-S \\
\hline 5 & Gullies & SSS, HF & N-S \\
\hline 6 & Wind-scoured, blowouts, and/or deposition areas & SSS & N-S \\
\hline 7 & Litter movement & SSS & N-S \\
\hline 8 & Soil surface resistance to erosion & SSS, $\mathrm{HF}, \mathrm{BI}$ & N-S \\
\hline 9 & Soil surface loss or degradation & SSS, HF, BI & N-S \\
\hline 10 & $\begin{array}{l}\text { Plant community composition and distribution } \\
\text { relative to infiltration and runoff }\end{array}$ & $\mathrm{HF}$ & $M-E$ \\
\hline 11 & Compaction layer & SSS, $\mathrm{HF}, \mathrm{BI}$ & N-S \\
\hline 12 & Functional/structural groups & $\mathrm{Bl}$ & E-T \\
\hline 13 & Plant mortality/decadence & $\mathrm{BI}, \mathrm{LCC}$ & N-S \\
\hline 14 & Litter amount & $\mathrm{HF}, \mathrm{BI}$ & E-T \\
\hline 15 & Annual production & $\mathrm{BI}, \mathrm{LCC}$ & N-S \\
\hline 16 & Invasive plants & $\mathrm{Bl}$ & $\mathrm{E}-\mathrm{T}$ \\
\hline 17 & Reproductive capability of perennial plants & $\mathrm{Bl}$ & N-S \\
\hline 18 & Percentage desirable forage plants & LCC & E-T \\
\hline 19 & Forage diversity & LCC & M \\
\hline 20 & Plant residue & $\mathrm{BI}, \mathrm{HF}, \mathrm{LCC}$ & M \\
\hline 21 & Percentage nontoxic legumes & LCC & E-T \\
\hline 22 & Uniformity of use & LCC & M \\
\hline 23 & Livestock concentration areas & LCC & N-S \\
\hline
\end{tabular}

et al. 2014). Based on our data, we have identified redundancies in ecologically based indicators of cover, erosion, compaction, and plant vigor. Since the IIRH method provides a standardized, site-specific way of evaluating these indicators, we recommend using these indicators instead. That places more focus on the following PCS indicators that are specifically related to the ability of an area to support a sustainable livestock grazing operation (LCC): percentage desirable forage species, forage plant diversity, plant residue, percentage legume, uniformity of use, and livestock concentration areas. There is one ecologically based indicator that PCS takes into account and IIRH does not: streambank and shoreline erosion. This is because IIRH is only designed to be applied to uplands. Riparian areas have a unique combination of soil and vegetation characteristics, as well as a specific set of policies and management rec- ommendations associated with them (e.g., NRCS policy on riparian areas in General Manual, 190-ECS, Issue-8, Part 411). Therefore, riparian areas should be evaluated separately using riparian specific methods, such as the Proper Functioning Condition (PFC; USDI 1998).

Nutrient management is an important aspect of grazingland optimization. The PCS methodology calls for a soil test when factors affecting plant vigor are rated low. For increasing the potential livestock production on grazinglands, we recommend at least annual monitoring of soil nutrient levels so that nutrient levels match optimum growing conditions for the desired forage species identified in a particular area.

Some of the ecologically based indicators, such as soil surface resistance to erosion, are commonly criticized as irrelevant in pastures because soil aggregate stability is often quite high. We found that when following NRI protocols (Spaeth et al. 2003) in healthy pastures, this indicator added little to no time where stability was high because the protocol excludes sample collection where there is high basal cover and root mats. In areas where cover was reduced, the indicator did reflect departure from reference conditions as expected. Increases in soil aggregate stability are not only telling of the erosion potential of an area, they can also be an indicator of soil health in a pasture. As organic matter in the soil increases, so does soil surface resistance to erosion (Tisdall and Oades 1982; Bird et al. 2002).

The indicators in table 7 can be integrated into existing ecologically based metrics for rangeland health in areas that are or will be managed for livestock production. Table 7 provides an evaluation matrix based on concepts taken from both PCS and IIRH and provides a way of evaluating indicators based on a specific site's ecological potential. The matrix in table 7 shows how each of these indicators is related to a LCC attribute and to other ecologically based attributes. In the example of the integrated assessment of plot 1 we show how integration provides a strong ecological foundation while adding a site specific approach to management interpretations. By using available ecological site descriptions and forage suitability group descriptions, users of this approach could identify deficiencies while at the same time determining site specific management approaches to address those deficiencies. Additionally, integrating assessment methodologies provides a more efficient field sampling approach that has an ecological foundation and can be used to provide management interpretations.

The approach described in this paper is for a qualitative assessment. These assessments can be complemented with standard quantitative measurements for a more accurate assessment (Pellant et al. 2005). These quantitative measurements should also be made where it is necessary to have supporting information and documentation and at locations where monitoring will take place (Pellant et al. 2005). Standardized grazingland assessment and monitoring protocols based on ecological and land management principles will ultimately improve the consistency of assessments and of national level data collection efforts, while providing a valuable 
Table 7

Proposed evaluation matrix of Pasture Condition Score (PCS) indicators used to determine livestock carrying capacity (LCC) as part of integrated grazingland health assessments (adapted from Cosgrove et al 2001 and Pellant et al. 2005). This matrix is to be used together with the matrix for evaluating soil and site stability, hydrologic function and biotic integrity (indicators 1 to 17 ) found in Interpreting Indicators of Rangeland Health (Pellant et al. 2005, pg. 82-87; available online at: http://jornada.nmsu.edu/files/IIRH_Forms.doc).

\begin{tabular}{|c|c|c|c|c|c|}
\hline $\begin{array}{l}\text { Indi- } \\
\text { cator } \\
\text { no. }\end{array}$ & $\begin{array}{l}\text { Core set of } \\
\text { qualitative } \\
\text { indicators }\end{array}$ & Attribute & Extreme to total & $\begin{array}{l}\text { Moderate to } \\
\text { extreme }\end{array}$ & Moderate \\
\hline 18 & $\begin{array}{l}\text { Percentage } \\
\text { desirable } \\
\text { forage plants }\end{array}$ & LCC & $\begin{array}{l}\text { Desirable forage } \\
\text { species }<20 \% \text { DW of } \\
\text { what is expected for } \\
\text { the Ecological Site } \\
\text { and/or Forage } \\
\text { Suitability Group. }\end{array}$ & $\begin{array}{l}\text { Desirable forage } \\
\text { species } 20 \% \text { to } 40 \% \\
\text { DW of what is } \\
\text { expected for the } \\
\text { Ecological Site } \\
\text { and/or Forage } \\
\text { Suitability Group. }\end{array}$ & $\begin{array}{l}\text { Desirable forage } \\
\text { species } 40 \% \text { to } 60 \% \\
\text { DW of what is } \\
\text { expected for the } \\
\text { Ecological Site } \\
\text { and/or Forage } \\
\text { Suitability Group. }\end{array}$ \\
\hline 19 & $\begin{array}{l}\text { Forage } \\
\text { diversity }\end{array}$ & LCC & $\begin{array}{l}\text { One dominant forage } \\
\text { species or no forage } \\
\text { species present. } \\
\text { Based on potential } \\
\text { forage species listed } \\
\text { in Forage Suitability } \\
\text { Group. }\end{array}$ & $\begin{array}{l}\text { Two forage species } \\
\text { and two or fewer } \\
\text { functional groups. } \\
\text { Large monoculture } \\
\text { patches common. } \\
\text { Based on potential } \\
\text { forage species listed } \\
\text { in Forage Suitability } \\
\text { Group. }\end{array}$ & $\begin{array}{l}\text { Three forage species } \\
\text { from three or fewer } \\
\text { functional groups. } \\
\text { Species distribution } \\
\text { shows a pattern not } \\
\text { expected for the site. } \\
\text { Based on potential } \\
\text { forage species listed } \\
\text { in Forage Suitability } \\
\text { Group. }\end{array}$ \\
\hline
\end{tabular}
Group.

Slight to moderate
Desirable forage
species $60 \%$ to $80 \%$
DW of what is
pected for the
Ecological Site
and/or Forage
Suitability Group.
Four forage species
representing at least
three functional
groups. Intermixed
well, compatible
growth habit and
comparable
palatability. Based
on potential forage
species listed in
Forage Suitability
Group.

\begin{tabular}{|c|c|c|c|}
\hline 20 & Plant residue & $\begin{array}{l}\mathrm{BI}, \mathrm{HF}, \\
\mathrm{LCC}\end{array}$ & $\begin{array}{l}\text { Standing dead } \\
\text { biomass }>25 \% \text { of } \\
\text { potential. Dead } \\
\text { biomass } \\
\text { accumulating into a } \\
\text { thick }(>2.5 \mathrm{~cm}) \\
\text { thatch layer. }\end{array}$ \\
\hline 21 & $\begin{array}{l}\text { Percentage } \\
\text { nontoxic } \\
\text { legumes }\end{array}$ & LCC & $\begin{array}{l}\text { If Forage Suitability } \\
\text { Group supports } \\
\text { legumes, Cool } \\
\text { season stands have } \\
\text { less than } 10 \% \text { by } \\
\text { weight. Or, greater } \\
\text { than } 60 \% \text { of bloating } \\
\text { legumes are present } \\
\text { Warm season stands } \\
\text { have less than } 4 \% \text { by } \\
\text { weight. }\end{array}$ \\
\hline
\end{tabular}

\begin{tabular}{|c|c|c|}
\hline $\begin{array}{l}\text { Standing dead } \\
\text { biomass } 15 \% \text { to } \\
25 \% \text { greater than } \\
\text { site potential. Dead } \\
\text { biomass accumu- } \\
\text { lating into a } 1 \text { to } 2.5 \\
\mathrm{~cm} \text { thatch layer. }\end{array}$ & $\begin{array}{l}\text { Standing dead } \\
\text { biomass } 5 \% \text { to } 15 \% \\
\text { greater than site } \\
\text { potential. Moderate } \\
\text { thatch buildup } \\
(<1 \mathrm{~cm}) .\end{array}$ & $\begin{array}{l}\text { Standing dead } \\
\text { biomass }<5 \% \text { of } \\
\text { expected based on } \\
\text { site potential. No } \\
\text { thatch buildup. }\end{array}$ \\
\hline $\begin{array}{l}\text { If Forage Suitability } \\
\text { Group supports } \\
\text { legumes, Cool } \\
\text { season stands have } \\
10 \% \text { to } 19 \% \text { by } \\
\text { weight. Warm } \\
\text { season stands have } \\
5 \% \text { to } 9 \% \text { by weight. }\end{array}$ & $\begin{array}{l}\text { If Forage Suitability } \\
\text { Group supports } \\
\text { legumes, Cool } \\
\text { season stands have } \\
20 \% \text { to } 29 \% \text { by } \\
\text { weight. Warm } \\
\text { season stands have } \\
10 \% \text { to } 19 \% \text { by } \\
\text { weight. }\end{array}$ & $\begin{array}{l}\text { If Forage Suitability } \\
\text { Group supports } \\
\text { legumes, Cool } \\
\text { season stands have } \\
30 \% \text { to } 39 \% \text { by } \\
\text { weight. Warm } \\
\text { season stands have } \\
20 \% \text { to } 29 \% \text { by } \\
\text { weight. }\end{array}$ \\
\hline
\end{tabular}

None to slight

Desirable forage

species exceed

$80 \%$ DW of what

is expected for the

Ecological Site

and/or Forage

Suitability Group.

Five forage species representing at

least three

functional groups.

Intermixed well,

compatible growth

habit and

comparable

palatability. Based

on potential

forage species

listed in Forage

Suitability Group.

Standing dead

biomass and dead biomass

accumulation as

expected based

on site potential.

If Forage

Suitability Group

supports

legumes, Cool

season stands

should have $40 \%$

to $60 \%$ by weight.

Warm season

stands should

have $30 \%$ to $40 \%$

by weight. If

legumes no

supported by

Forage Suitability

Group rate as N-S. forage species are rejected only present at urine and dung patches.

\begin{tabular}{llll}
\hline 22 Uniformity & LCC & Little-grazed or & Little-grazed or \\
of use & ungrazed patches & ungrazed patches \\
& where forage species & where forage \\
& are rejected cover & species are rejected \\
& over 50\% of the area. & cover 26\% to 50\% \\
& Rejected patches are & of the area. Patches \\
& generally connected. & are occasionally \\
& & connected.
\end{tabular}

Little-grazed or

ungrazed patches

where forage

species are rejected

cover $10 \%$ to $25 \%$

of the area. Patches

sporadically

connected.

Light-grazed or
ungrazed and
unconnected
patches where
forage species are
rejected are small
and isolated ( $<10 \%$
cover). Urine and
dung patches
avoided.

\begin{tabular}{|c|c|c|}
\hline 23 & $\begin{array}{ll}\text { Livestock } & \text { LCC } \\
\text { concentration } & \\
\text { areas } & \end{array}$ & $\begin{array}{l}\text { Cover }>10 \% \text { of the } \\
\text { pasture and } \\
\text { transport } \\
\text { contaminated runoff } \\
\text { directly into water } \\
\text { channels. }\end{array}$ \\
\hline
\end{tabular}

\section{Livestock \\ Isolated and}

concentration areas

and trails cover $5 \%$

to $10 \%$ of the area

and drain into water

channels unbuffered. unconnected

livestock

concentration areas

and trails $(<5 \%$ of

area); can potentially

drain into water

channels unbuffered.
Some livestock trails

and one or two small

and unconnected

concentration areas.

If present, areas

have been treated

to prevent

contaminated runoff.
No presence of livestock concentration areas or heavy use areas. 


\section{Figure 2}

Attribute ratings for the integrated grazingland health assessment at plot 1 of the Northern Great Plains Research Laboratory. Attribute rating is based on the rating of each of the 23 indicators and the preponderance of evidence. Numbers in the figure correspond to each one of the three indicators. For example, percentage bare ground (indicator \#4) was rated as none to slight (N-S). This indicator is related to soil and site stability (SSS), hydrologic function (HF), and livestock carrying capacity (LCC) so a number 4 is placed in the N-S column for each of these attributes.

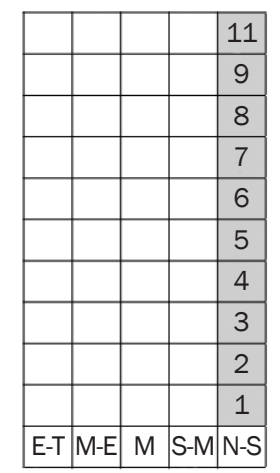

Soil and site stability

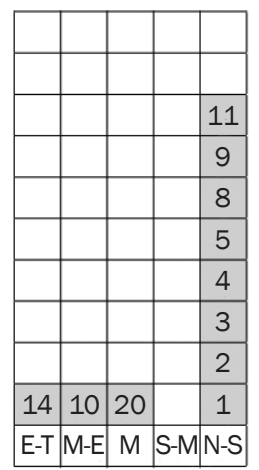

Hydrologic function

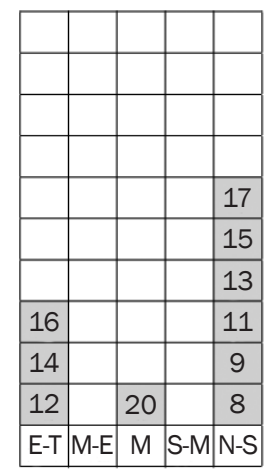

Biotic integrity

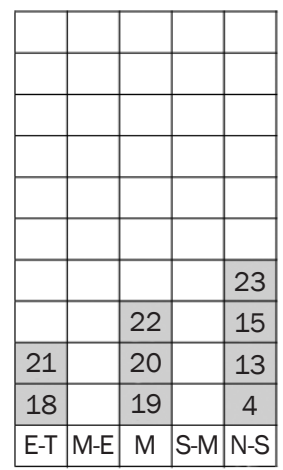

Livestock carrying capacity and efficient tool for assessing, managing, and monitoring grazinglands.

\section{Summary and Conclusions}

There is a need for an improved grazingland assessment tool that merges elements of both the IIRH and PCS assessment methods while taking into account the differing ecosystem attributes and management objectives of the grazinglands where these methods are usually applied. We use IIRH and PCS data collected at two locations in the Northern Great Plains of the United States to describe an improved assessment and monitoring protocol that allows evaluators to assess site conditions and to make interpretations regarding management based on site-specific attributes. This new approach, combined with proper adaptive management, can potentially help optimize the ecological potential and livestock carrying capacity of a site.

\section{Acknowledgements}

This work was supported by funds from a Conservation Effects Assessment Project jointly funded by the USDA Natural Resources Conservation Service and the Agricultural Research Service.

\section{References}

Bird, S.B., J.E. Herrick, M.M. Wander, and S.F.Wright. 2002 Spatial heterogeneity of aggregate stability and soil carbon in semi-arid rangeland. Environmental Pollution 116:445-455.

Briske, D.D. (ed). 2011. Conservation benefits of rangeland practices: Assessment, recommendations, and knowledge gaps, 429. Washington, DC: USDA Natural Resources Conservation Service.

Bryan, W.B. 1985. Effects of sod-seeding legumes on hill land pasture productivity and composition. Agronomy Journal (77):901-905.

Butler, L., J. Cropper, R. Johnson, A. Norman, and P. Shaver. 2003. National Range and Pasture Handbook. Washington, DC: USDA Natural Resources Conservation Service.

Cosgrove, D., D. Undersander, and J.B. Cropper. 2001. Guide to Pasture Condition Scoring. Fort Worth, Texas. Washington, DC: USDA Natural Resources Conservation Service, Grazing Lands Technical Institute.

Duniway, M.C., J.E. Herrick, D.A. Pyke, and D. Toledo P. 2010. Assessing transportation infrastructure impacts on rangelands: Test of a standard rangeland assessment protocol. Rangeland Ecology and Management 63(5):524-536.

Herrick, J.E., V.C. Lessard, K.E. Spaeth, P.L. Shaver, R.S. Dayton, D.A. Pyke, L. Jolley, and J.J. Goebel. 2010. National ecosystem assessments supported by local and scientific knowledge. Frontiers in Ecology and the Environment 8:403-408.

Goslee, S., M. Sanderson, K. Spaeth, J. Herrick, and K. Ogles. 2014. An ecologically based landscape classification system for monitoring and assessment of pastures. Journal of Soil and Water Conservation 69(1):17A-21A, doi:10.2489/jswc.69.1.17A.

Jin, S., L. Yang, P. Danielson, C. Homer, J. Fry, and G. Xian. 2013. A comprehensive change detection method for updating the National Land Cover Database to circa 2011. Remote Sensing of Environment 132:159-175.

Morgan, R.P.C. 1986. Soil erosion and conservation. Harlow, UK: Longman Scientific and Technical, New York: Wiley. Nelson, C.J. (ed). 2012. Conservation outcomes from pastureland and hayland practices: Assessment, recommendations, and knowledge gaps. Lawrence, KS: Allen Press.
Pellant, M., P. Shaver, D.A. Pyke, and J.E. Herrick. 2005. Interpreting indicators of rangeland health, version 4. Technical Reference 1734-6. Denver, CO: US Department of the Interior, Bureau of Land Management, National Science and Technology Center. Sanderson, M.A. 2014. Evaluating the USDA NRCS pasture condition score system with weighted indicators. Ecological Indicators 41:183-186.

Sanderson, M.A., S.C. Goslee, J. Gonet, and R. Stout. 2009. Pasture monitoring at a farm scale with the USDA NRCS pasture condition score system. Journal of Soil and Water Conservation 64(6):423-433, doi:10.2489/ jswc.64.6.423.

Spaeth, K.E., F.B. Pierson, J.E. Herrick, P.L. Shaver, D.A. Pyke, M. Pellant, D. Thompson, and B. Dayton. 2003. New proposed national resources inventory protocols on nonfederal rangelands. Journal of Soil and Water Conservation 58(1):18A-21A.

Tilman, D., J. Knops, D. Wedin, P. Reich, M. Ritchie, and E. Siemann 1997. The influence of functional diversity and composition on ecosystem processes. Science 277:1300-1302.

Tisdall, J.M., and J.M. Oades. 1982. Organic matter and water-stable aggregates in soils. Journal of Soil Science 33:141-163.

Toevs, G.R., J.W. Karl, J.J. Taylor, C.S. Spurrier, M.S. Karl, M.R. Bobo, and J.E. Herrick. 2011. Consistent indicators and methods and a scalable sample design to meet assessment, inventory, and monitoring information needs across scales. Rangelands 33(4):14-20.

Toledo, D., M. Sanderson, J. Herrick, and S. Goslee. 2014. An integrated approach to grazingland ecological asessments and management interpretations. Journal of Soil and Water Conservation 69(4):110A-114A, doi:10.2489/jswc.69.4.110A.

USDI (Department of Interior). 1998. Riparian area management: Process for assessing proper functioning condition. USDI Bureau of Land Management, Proper Functioning Condition Work Group. http://www. blm.gov/nstc/library/pdf/Final\%20TR\%201737-9.pdf. USDA NRCS (Natural Resources Conservation Service). 2009. National Resources Inventory grazing land onsite study: Handbook of instructions. Washington, DC: USDA Natural Resources Conservation Service.

USDA NRCS. 2011. Ecological Site Description. Ecological Site Description (ESD) System for Rangeland and Forestland. https://esis.sc.egov.usda.gov/Welcome/ pgESDWelcome.aspx. 